National Ignition Facility

Computational Fluid Dynamics Modeling and Light Fixture Case Studies

Richard Martin

John Bernardin

Lucie Parietti

Bruce Dennison
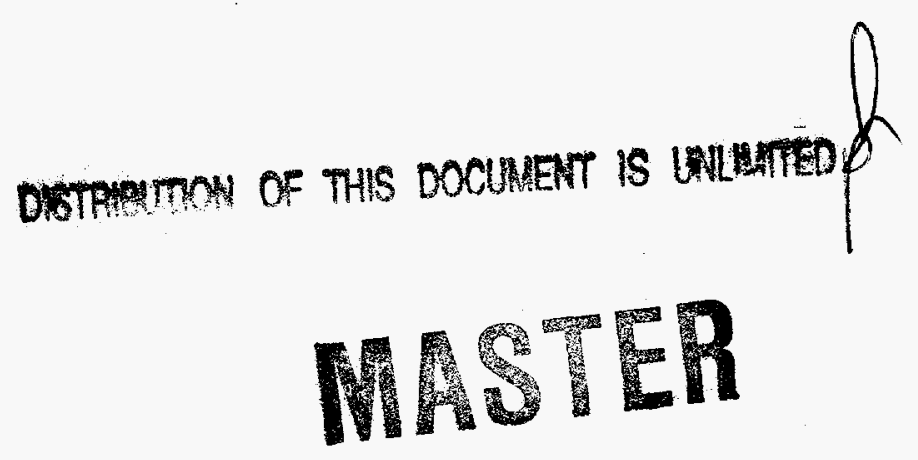


\section{DISCLAIMER}

This report was prepared as an account of work sponsored by an agency of the United States Government. Neither the United States Government nor any agency thereof, nor any of their employees, makes any warranty, express or implied, or assumes any legal liability or responsibility for the accuracy, completeness, or usefulness of any information, apparatus, product, or process disclosed, or represents that its use would not infringe privately owned rights. Reference herein to any specific commercial product, process, or service by trade name, trademark, manufacturer, or otherwise does not necessarily constitute or imply its endorsement, recommendation, or favoring by the United States Government or any agency thereof. The views and opinions of authors expressed herein do not necessarily state or reflect those of the United States Government or any agency thereof. 


\section{DISCLAIMER}

Portions of this document may be illegible electronic image products. Images are produced from the best available original document. 


\section{TABLE OF CONTENTS}

ABSTRACT 1

I. Background and Objectives

A. NIF Title I and Title II CFD Applications

1. Parsons/CAES HVAC Verification

2. FOA Pump-Down and Venting (Thermal Upset and Design)

3. Beam Tube Proximity to Light Fixtures

4. Wavefront Distortion Induced by Lorentz Flows Inside Beam Tubes

B. NIF CFD Review

C. CFD Calculations for Benchmarking

D. Objectives

II. CFD Self-Consistency Checks and Accuracy

2
A. Grid Independence
B. Convergence
C. Mass and Energy Balances
D. Double Precision
E. Accuracy - How Meaningful are the Results?

III. Importance of Capturing Fluid Mechanics and Heat Transfer Phenomena 5
A. Turbulence Modeling
B. Buoyancy-Driven Flows
C. Radiation Heat Transfer
D. Temperature-Dependent Properties

IV. Importance of Choice of Boundary Conditions
A. Types
B. Code Implementation
C. Relevance to NIF Modeling
D. Modeling Light Fixtures

V. CFD Simulations of Thermal Interactions between a NIF Light Fixture, Beam Tube, and the HVAC Airflow (Light Fixture Case Studies)
A. Software and Hardware
B. Model Geometry, Boundary Conditions, and Grid Discretization
C. Convergence Criteria
D. Results

VI. Summary Remarks and Conclusions 


\title{
National Ignition Facility Computational Fluid Dynamics Modeling and Light Fixture Case Studies
}

\author{
by \\ Richard Martin, John Bernardin, Lucie Parietti, and Bruce Dennison
}

\begin{abstract}
This report serves as a guide to the use of computational fluid dynamics (CFD) as a design tool for the National Ignition Facility (NIF) program Title I and Title II design phases at Lawrence Livermore National Laboratory. In particular, this report provides general guidelines on the technical approach to performing and interpreting any and all CFD calculations. In addition, a complete CFD analysis is presented to illustrate these guidelines on a NIF-related thermal problem.
\end{abstract}




\section{Background and Objectives}

During the National Ignition Facility (NIF) program Title I and Title II phases, computational fluid dynamics (CFD) methods have been used to provide engineering design and analysis support in several areas including: (1) Parsons/CAES heating, ventilation, and air conditioning (HVAC) verification, (2) final optics assembly (FOA) pump-down and venting (thermal upset and design), (3) beam tube proximity to light fixtures, and (4) wavefront distortion induced by Lorentz flows inside beam tubes. The prime contractor, Parsons, Inc., and its consultant, CAES, have performed CFD calculations to determine air velocity and temperature fields in NIF produced by the HVAC system design.

Los Alamos was tasked to review the work described above in 1 and to perform CFD design calculations in areas 2 to 4 . In some cases, the Los Alamos CFD calculations are used to benchmark hand calculations or calculations using the SINDA/FLUINT lumped-parameter code.

The objectives of this report are to provide general guidelines on the technical approach to performing and interpreting any and all CFD calculations, and to document results from NIF-related, two-dimensional CFD light fixture case studies illustrating these guidelines and pertaining to area 1.

\section{CFD Self-Consistency Checks and Accuracy}

Performing a CFD calculation involves defining the problem geometry, discretizing the solution domain (preparing a grid), imposing boundary conditions, and selecting physical models. When these steps are complete the CFD code is run to 
calculate fluid mechanics and heat transfer phenomena and the results are studied. While the process seems fairly straightforward, there are details and complications that can lead to lack of convergence and long computer run times.

By virtue of mathematical modeling the use of CFD involves approximations, so we are always concerned about the veracity of results. To obtain meaningful results, several CFD self-consistency checks should be performed, including grid independence, convergence, and mass and energy balances.

Preparing a "good" grid is essential and can make the difference between obtaining a solution and not. More orthogonal grids produce more accurate results and fewer problems with convergence. Ideally, several successively refined grids could be run until the computed results stop changing. However, for large problems it may not be feasible to double the number of grid elements to assess the effects of grid refinement. In such cases it may be possible to refine the grid only in critical areas or areas of high gradients and/or to use a more accurate (than first-order) differencing scheme if the grid is pretty good to begin with. Grids must be sufficiently refined near walls to properly deal with viscous boundary layer effects (area reduction and separation) and thermal boundary layer effects (heat input or removal). However, there is a dilemma in this area because more computational cells translate into longer computer runs, especially for 3-D problems where doubling the grid density in three coordinate directions increases the number of computational cells by a factor of 8 .

Convergence of a CFD calculation to the correct solution is obtained when the "residuals" of all the computed variables have been reduced at least 3 orders of magnitude, as a rule-of-thumb. The residual for a given variable, say $u, v, w, p, h, K$, or 
$\varepsilon$, is the difference between the right- and left-hand sides of the algebraic equation for this variable summed over the whole grid. With each pass through the segregated solver (sequential solution of equations), these residuals should become smaller if the solution is converging. For transient calculations, the time step size plays a role in convergence.

Another essential self-consistency check of a CFD calculation is to insure accurate mass and energy balances, that is, conservation of mass and energy. Typically, we try to converge the outlet mass flow rate to within $0.1 \%$ of the incoming mass flow rate, whereas for qualitative calculations $1 \%$ may be sufficient. On the energy (or enthalpy) we desire a balance to within $1 \%$; but, for buoyancy-driven flows this may be difficult to achieve and we might settle for $5 \%$ to $10 \%$.

For CFD design problems like those associated with the NIF, namely, buoyancydriven flows, or flows in large facilities, or flows where very small temperature differences play an important role, we have found that double-precision arithmetic is mandatory to obtain much more accurate and meaningful results.

Sometimes our lack of knowledge of physical properties of a problem plays a role in determining the accuracy of results, for example, the emissivity of a surface may not be well characterized, nor may the turbulent behavior of the fluid be well understood. However, it is possible to perform sensitivity studies, we make conservative assumptions, and we apply engineering judgment. Ultimately, CFD calculations should be benchmarked against experimental data where possible. Laminar flows and conduction heat transfer can be calculated very accurately. In general, we can resolve to within approximately $1 \%$. 


\section{Importance of Capturing Fluid Mechanics and Heat Transfer Phenomena}

The relative importance of turbulence, buoyancy, radiation, and temperature dependence of properties are physics phenomena that should be assessed in each problem using hand calculations. The NIF flow and thermal fields are produced by a large-scale HVAC flow situation with moderate heat addition primarily from the light fixtures.

In the NIF, the flow condition is expected to be turbulent based on Reynolds number calculations; therefore, the effects of increased shear and mixing should be included by using an appropriate turbulence model in CFD calculations. The "standard" two-equation $\mathrm{K}-\varepsilon$ model [1] has been used and has generally been accepted as appropriate.

The relative importance of fluid buoyancy compared with fluid inertia can be quantified by comparing the Grashof number (buoyant to viscous forces) to the Reynolds number (inertia to viscous forces) squared [2]. If this ratio is greater than approximately 1.0 , then the flow is buoyancy-dominated. We have found this to be the case outside but near the NIF beam tubes, as well as inside the beam tubes. This condition is true even though the beam tube wall temperatures may only be a few tenths of a degree Celsius higher than the fluid temperature. Consequently, buoyancy terms must be included in the momentum equations for NIF CFD calculations.

While it is tempting to neglect radiation heat transfer for temperatures near ambient and for small temperature differences to save computational complexity and computer time, this approach for NIF-type flows neglects an important heat transfer mechanism as we will show in Sec. V. Several studies $[3,4,5,6]$ have shown that, for numerical models of free convection in enclosures, the flow and temperature fields are 
strongly dependent on radiation heat transfer. Consequently, to obtain an accurate representation of the thermal fields in numerical models of free convection, radiation heat transfer must be included.

\section{Importance of Choice of Boundary Conditions}

After setting up a CFD problem geometry and preparing a suitable grid, boundary conditions must be specified for flow inlets and outlets and for walls. Wall boundary conditions include adiabatic, constant heat flux, constant temperature, and symmetric.

For turbulent flows, such as in the NIF, a "law-of-the-wall" approximation [7] is often assumed to reduce the number of grid cells required near heating or cooling walls. The law-of-the-wall assumption provides a semi-empirical curve fit to velocity and temperature versus distance profiles near walls over a single cell. These profiles are needed to determine velocity and temperature gradients at the wall surface for calculation of shear stresses and conduction heat transfer. The criterion of $35<=y^{+}<=350$, where the inner variable $\mathrm{y}^{+}$is a dimensionless distance used in law-of-the-wall equations for velocity and temperature versus distance from the wall, should be met.

For each boundary condition case, it is important for modeling purposes to understand how the CFD code implements the boundary condition. For example, in the case of constant heat flux defined for a given wall area in the absence of radiation, the code will calculate a wall temperature (using the law-of-the-wall) consistent with conducting the entire specified amount of heat into the adjacent cells of fluid. If radiation is turned on, the code will calculate a wall temperature consistent with both conducting and radiating heat into the fluid, while maintaining the same specified heat flux. With 
radiation, the constant heat flux wall temperature will be lower than the wall temperature without radiation. In both cases, the amount of heat delivered to the flow will be the same.

In the case of constant temperature defined for a given wall area in the absence of radiation, the code will calculate a conduction heat flow into the adjacent fluid (using the law-of-the-wall) depending on the fluid temperature in the first cell near the wall. If radiation is turned on, the code will calculate a larger heat flow representing both conduction and radiation from the surface.

In some areas of the NIF lighting is the major space heat load component. For CFD computation of the steady-state velocity fields and temperature fields (which can affect beam pointing) in these areas, two questions arise. The first is how do we model the light fixtures, and the second is whether or not it is necessary to include radiation heat transfer in the calculations.

It has been observed in [8] that "Only part of the energy from lights is from convective heat, which is picked up instantaneously by the air conditioning apparatus. The remaining portion is in the form of radiation that affects the conditioned space once it has been absorbed and re-released by the walls, floors, furniture, etc. This absorbed energy contributes to space cooling load only after a time lag, so part of this energy is reradiated...." Thus, for NIF we expect the light fixtures to contribute heat to the interior spaces both by convection and by radiation (or re-radiation). Reference [8] recommends an additional "special allowance factor" of 1.2 in general applications to account for ballast losses when determining lighting heat loads. 
The energy distribution between convection and radiation for non-recessed, nonventilated, fluorescent light fixtures is estimated to be $29 \%$ and $58 \%$, respectively, with $13 \%$ conduction losses [9]. A recent Los Alamos experimental study of a typical fluorescent fixture yielded $38 \%, 52 \%$, and $10 \%$ for this energy distribution [10].

It is evident that radiant energy plays a significant role in the modeling of light fixtures. For a CFD light fixture model a choice must be made between using a constant heat flux or a constant temperature boundary condition on a wall (ceiling) to simulate the heat release. The consequences of one choice or the other are investigated in Sec. V.

\section{CFD Simulations of Thermal Interactions Between a NIF Light Fixture, Beam Tube, and the HVAC Airflow}

The purpose of the four NIF-related case studies presented here is to investigate the same two questions: (1) how can we best model NIF light fixtures, and (2) is it important to include radiation in NIF calculations?

The results were obtained with CFX (CFX4), a mature, commercial, full-physics, industry-driven CFD computer code that has been developed under ISO 9001 requirements, and has been validated with numerous test problems. We have found the CFX code to be relatively "user-friendly" with good post-processing capabilities. CFX was formerly known as CFDS-FLOW3D.

The CFX modeling capabilities used in this study were two-dimensional, steady state, incompressible, turbulent, buoyant flow (Boussinesq approximation), with conjugate heat transfer, and a Monte Carlo radiation exchange routine. For conjugate heat transfer, the code will calculate conduction heat transfer within a solid object and, 
simultaneously, convection heat transfer to a fluid from the solid surfaces, as well as radiation exchange between surfaces.

(The reader may be interested in certain CFX capabilities available, but not used in this study. For example, CFX has the capability to handle unsteady or transient problems, weakly or fully compressible fluids, multiphase with evaporation, condensation, particulate transport, non-Newtonian fluids, chemical species concentration, chemical reacting flows, porous media, and conjugate heat transfer flows. A discrete, or Shah radiation exchange model is available to speed up calculations. CFX also has a versatile user FORTRAN capability that allows the user to add custom subroutines.)

CFX features grid generation flexibility using a multi-block scheme with bodyfitted grids, that is, grid boundaries that fit or map to the geometry. CFX models complex structures as an assemblage of "blocks." While the hexahedral grid structure within each block is "structured," the overall global connectivity of the blocks is essentially free or unstructured. It also has the capability to do moving, sliding, rotating, and globally unstructured grids.

CFX has CAD compatibility with UG, ProE, PATRAN, IDEAS, and does not have to depend on IGES graphical exchanges.

Regarding numerics, CFX is a finite volume, implicit, Navier-Stokes solver with automatic timestep control. The numerics are based on the semi-implicit method for pressure-linked equations (SIMPLE) technique for the solution of three-dimensional parabolic flows developed by Patankar and Spalding [11], and later enhanced by Van Doormaal and Raithby (SIMPLEC) [12]. The CFX code uses well-developed solvers (to 
solve simultaneous, algebraic equations) and differencing schemes as appropriate for different flow situations.

Regarding hardware, for design engineering calculations at Los Alamos National Laboratory, three floating licenses of CFX4 are installed on four dedicated computers, two SGI Indigo IIs, and two faster, larger capacity Dec Alpha workstations in the Design Engineering Group. For the calculations reported here, we used an SGI containing a single $250 \mathrm{MHz}$ IP22 processor and $256 \mathrm{MB}$ of main memory. This machine also contains two SCSI 4 GB hard disks, and its graphics board is a GR3-Elan. The floating point chip is an MIPS R4010 Rev 0, and the processor chip is an MIPS R4400 Rev 6.0.

The geometrical model used for the four case studies is shown in Figure 1. A two-dimensional geometry, which accurately describes a typical fluorescent light fixture configuration in the NIF laser bays, was used to simplify the problem but still yield meaningful results. In this model, a downward flow of air is directed through the ceiling inlets at $12.5 \mathrm{ft} / \mathrm{min}(0.0635 \mathrm{~m} / \mathrm{s})$, passes over a single beam tube (containing a four by two matrix of rectangular laser beams), and exits through an outlet modeled as an atmospheric pressure boundary. The beam tube was modeled as a conducting solid with a thermal conductivity, density, and specific heat that were weighted using the corresponding values and cross-sectional areas of stainless steel and air. 
Notes: All dimensions in meters

depth into page $=1.219$

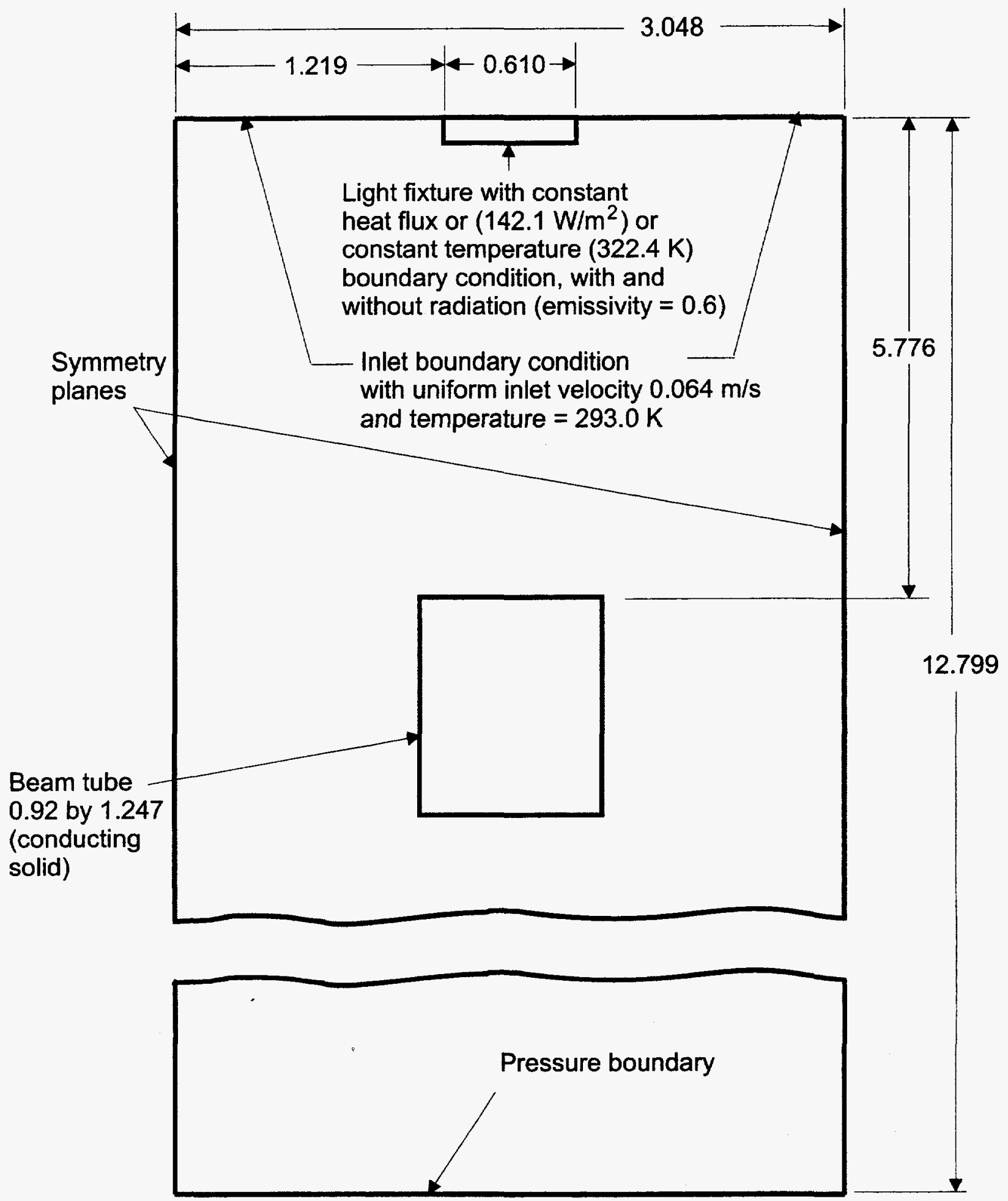

Figure 1. Geometrical model and boundary conditions for the CFX light fixture analysis. 
For example, the thermal conductivity of the solid beam tube, $k_{\text {ref }}$, was determined as follows:

$$
k_{\text {ref }}=k_{\text {air }} A_{\text {air }} /\left(A_{\text {air }}+A_{\text {steet }}\right)+k_{\text {steel }} A_{\text {steel }} /\left(A_{\text {air }}+A_{\text {steee }}\right)
$$

where values of $0.003 \mathrm{~m}^{2}$ and $1.0 \mathrm{~m}^{2}$ were used for the cross-sectional areas of the air, $A_{\text {air }}$, and steel, $A_{\text {steel }}$, respectively. This technique gave respective values of $0.07 \mathrm{~W} /(\mathrm{m} \mathrm{K})$, $25.09 \mathrm{~kg} / \mathrm{m}^{3}$, and $1005 \mathrm{~J} /(\mathrm{kg} \mathrm{K})$ for the thermal conductivity, density, and specific heat of the solid beam tube. Using this modeling technique, the thermal response of the beam tube model was estimated to be fairly representative of the behavior of an actual beam tube.

In the middle of the ceiling, a single surface heat source was defined to model a fluorescent light fixture using either a constant surface temperature $(322.4 \mathrm{~K})$ or constant surface heat flux $\left(142.1 \mathrm{~W} / \mathrm{m}^{2}\right)$ approach. It seems prudent for ultra-temperature sensitive applications like NIF to be conservative in adding heat to the flow domain. If the power rating on a light fixture is $106 \mathrm{~W}$, a method of insuring that $106 \mathrm{~W}$ gets into the flow domain must be used. Either a constant heat flux boundary condition, in which the full $106 \mathrm{~W}$ is divided by the area of the light fixture, should be employed, or a constant surface temperature boundary condition should be selected in such a way that $106 \mathrm{~W}$ is transported across the boundary. In the present model, the fluorescent light, a three bulb (32 $\mathrm{W}$ per bulb) fixture with a total heat dissipation rate of $106 \mathrm{~W}$ (from the light bulbs and voltage regulating ballast) [10], was used in the model since it is representative of the majority of the light fixtures in NIF laser bays. For the cases involving radiation heat 
transfer, the value of emissivity for the light fixture was adjusted to 0.6 to provide approximately a $30 \%$ and $70 \%$ division between convection and radiation heat transfer, respectively, from the light source [10]. For model simplicity, only the lower half of the light fixture was used in the present geometry. This was justified since the described light fixture dissipates roughly $70 \%$ of its heat by radiation (visible and infrared wavelengths) in a downward direction for a downward facing fixture. An experimental investigation of the heat dissipation characteristics of a fluorescent light fixture and a similar modeling approach are discussed in detail [10].

Finally, the left and right sides of the model were set as symmetry planes, based upon a representative center-to-center light spacing used in the NIF. While this model attempts to mock a section of the NIF laser bay geometry, its main purpose is to illustrate modeling of a light fixture. Consequently, since the geometry does not correspond exactly to the real NIF geometry in a particular laser bay location, the reader is cautioned to interpret the results carefully.

A uniform grid with a center-to-center cell spacing of $2.54 \mathrm{~mm}$ ( 1 in.) was used with the present model which resulted in a total number of 60288 computational cells. This grid discretization was determined to be adequate in capturing the temperature and velocity gradients near the light fixture and beam tube.

Hand calculations of fluid mechanics dimensionless numbers are essential to characterize the physical processes and to select CFD physical models. Accordingly, the Reynolds and Grashof numbers were calculated to determine if buoyancy forces are significant in the flow fields around the beam tube. 
The dimensionless Reynolds number, which represents a ratio of the inertia and viscous forces in a fluid flow, is given by

$$
R e=u L / v
$$

where $u$ is the fluid velocity, $L$ is a characteristic length of the geometry, and $v$ is the kinematic viscosity of the fluid.

The dimensionless Grashof number, which represents a ratio of the buoyancy and viscous forces of a fluid flow, is defined as

$$
G r=g \beta\left(T_{s}-T_{\infty}\right) L^{3} / v^{2}
$$

where $\mathrm{g}=9.8 \mathrm{~m} / \mathrm{s}^{2}$ and $\beta=2 /\left(T_{s}+T_{\infty}\right)$ for a perfect gas.

For the beam tube dimensions of $1.247 \mathrm{~m}$ by $0.920 \mathrm{~m}$, the characteristic length is the hydraulic diameter $(L=4 A / P)$, or $1.059 \mathrm{~m}$. Using an air inlet velocity, $\mathrm{u}=$ $0.0635 \mathrm{~m} / \mathrm{s}$, a kinematic viscosity, $v=15.89 * 10^{-6} \mathrm{~m}^{2} / \mathrm{s}$, and $\left(T_{s}-T_{\infty}\right)=0.3^{\circ} \mathrm{C}$ for the temperature difference between the beam tube surface and the free stream, values of 4265 and $4.725 * 10^{7}$ were determined for the Reynolds and Grashof numbers, respectively.

The ratio $\mathrm{Gr} /(\mathrm{Re})^{2}$ is used to assess the relative importance of buoyancy to inertia forces, $\mathrm{Gr} /(\operatorname{Re})^{2}>1$ indicates buoyancy forces dominate, $\mathrm{Gr} /(\operatorname{Re})^{2}<1$ indicates inertia forces dominate. Using the above values for $G r$ and $R e$, a ratio $\mathrm{Gr} /(\mathrm{Re})^{2}=2.597$ was obtained, thus indicating that buoyant forces will dominate the external flow field near the beam tubes. 
The operating conditions selected for the CFD model included two-dimensional, steady-state, incompressible, turbulent, buoyant flow with heat transfer. To accurately model the mild turbulence encountered in this study, the two equation $k-\varepsilon$ model was employed. Values of $k$ and $\varepsilon$ used in the CFX model were determined to be $k=0.002$ * $u^{2}=8.07 * 10^{-6} \mathrm{~m}^{2} / \mathrm{s}^{2}$, and $\varepsilon=k^{1.5} /(0.3 * L)=3.01 * 10^{-4} \mathrm{~m}^{2} / \mathrm{s}^{3}$. For the cases including radiation exchange, a Monte Carlo method was used for convenience. Because of the high sensitivity of the operating performance of the NIF beam tubes to small temperature excursions $\left(\approx 0.1^{\circ} \mathrm{C}\right)$, calculations were performed using double-precision arithmetic.

To determine the convergence and credibility of the CFX model, a three-step validation procedure of the numerical solution was employed. First and foremost, the convergence of a model onto a solution was determined with residuals. In the solution algorithm of CFX, each dependent variable, $y$ (e.g., temperature), is solved for in algebraic equations of the form

$$
f(y)=F
$$

where $F$ is a forcing function.

The residual for the dependent variable $y$ is the error or difference between the left- and right-hand sides of Eq. 4. The residuals for each dependent variable were determined at each cell and summed over all cells for a single iteration. A converged solution was obtained when the sum of the residuals for each dependent variable ceased to vary between consecutive iterations. 
The final two tests of convergence were mass and energy balances of the model system. For the qualitative steady-state problems considered in this study, convergence was assumed when there was less than a $5 \%$ difference in the inlet and outlet flows of mass and energy.

Figure 2 through Figure 5 present velocity vector and temperature contour plots as predicted with the respective following four light fixture boundary condition models:

1. constant surface heat flux of $142.1 \mathrm{~W} / \mathrm{m}^{2}$ without radiation heat transfer, 2. constant surface heat flux of $142.1 \mathrm{~W} / \mathrm{m}^{2}$ with radiation heat transfer, 3. constant surface temperature of $322.4 \mathrm{~K}$ with radiation heat transfer, and 4. constant surface temperature of $322.4 \mathrm{~K}$ without radiation heat transfer.

In all four temperature contour plots of Figure 2 through Figure 5, the same temperature scale has been used to allow for direct comparison. A summary of the light surface temperatures and heat transfer rates by convection and radiation from the light fixture is given in Table 1. A discussion of the individual results for each of the four models is presented following Table 1 . 
Table 1. Summary of light fixture surface temperatures and heat transfer rates defined or numerically predicted for various CFX light fixture model boundary conditions.

\begin{tabular}{|l|c|c|c|c|}
\hline \multirow{2}{*}{ Parameter } & \multicolumn{4}{|c|}{ Light fixture modeling boundary condition } \\
\cline { 2 - 5 } & $\begin{array}{l}\text { Constant heat } \\
\text { flux without } \\
\text { radiation }\end{array}$ & $\begin{array}{l}\text { Constant heat } \\
\text { flux with } \\
\text { radiation }\end{array}$ & $\begin{array}{l}\text { Constant } \\
\text { surface } \\
\text { temperature } \\
\text { with radiation }\end{array}$ & $\begin{array}{l}\text { Constant } \\
\text { surface } \\
\text { temperature } \\
\text { without } \\
\text { radiation }\end{array}$ \\
\hline $\begin{array}{l}\text { Light surface } \\
\text { temperature (K) }\end{array}$ & 391.9 & 322.4 & 322.4 & 322.4 \\
\hline $\begin{array}{l}\text { Light } \\
\text { emissivity }\end{array}$ & NA & 0.6 & 0.6 & NA \\
\hline $\begin{array}{l}\text { Convection } \\
\text { heat transfer } \\
\text { rate (W) }\end{array}$ & $105.6(100 \%)$ & $24.6(23 \%)$ & $24.9(24 \%)$ & $24.7(23 \%)$ \\
\hline $\begin{array}{l}\text { Radiation heat } \\
\text { transfer rate } \\
\text { (W) }\end{array}$ & 0.0 & $81.0(77 \%)$ & $80.7(76 \%)$ & 0.0 \\
\hline $\begin{array}{l}\text { Total heat } \\
\text { transfer rate } \\
\text { (W) }\end{array}$ & 105.6 & 105.6 & 105.6 & 24.7 \\
\hline
\end{tabular}

Figure 2 presents results from the light fixture boundary condition corresponding to a constant surface heat flux without radiation heat transfer. Because all $105.6 \mathrm{~W}$ of energy being dissipated by the light fixture must enter the flow by conduction from the light fixture surface into the first layer of cells of fluid along the surface (this can be thought of as a convective heat transfer process), the wall temperature on the surface is determined by the code to be an unrealistic $391.9 \mathrm{~K}$ ! This high temperature, compared with the incoming air temperature of $293.0 \mathrm{~K}$, produced a steep temperature gradient to go with the steep velocity gradient near the edges of the light fixture, creating numerical convergence problems with CFX early in the study. 


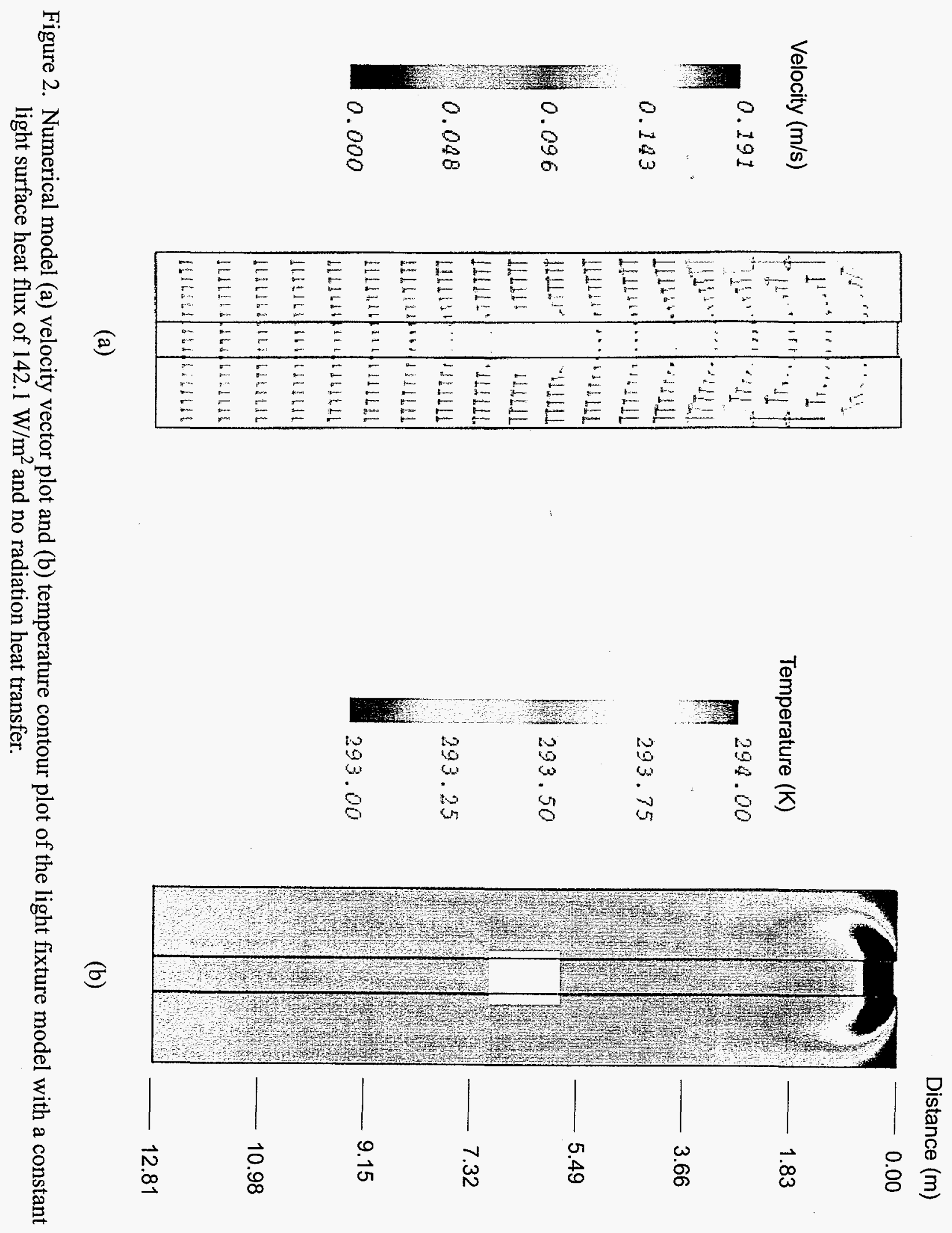



Because the air below and near the edges of the light fixture in Figure 2 is exposed to a $391.9 \mathrm{~K}$ surface and is receiving $105.6 \mathrm{~W}$ of heat, buoyancy forces attempt to drive the air sideways, if not upwards, in the presence of the imposed downward flow. The effect is to produce an "umbrella" of warm low-energy flow under the light fixture that wants to go up or outward, not down. In a 4-m-long region directly beneath the light fixture, air is recirculated from the downward flowing stream and drawn upward back towards the light fixture where it is heated and then forced outward in a sideways motion to join back up with the main downward flowing stream. In Figure 2(b) the temperature field produced by $105.6 \mathrm{~W}$ heat dissipation is seen to be highly localized in a "mushroom cap" below the light fixture to an extent of roughly $2 \mathrm{~m}$. However, the heat quickly dissipates by conduction and advection throughout the downward flow, creating a uniform airflow that is approximately $0.5^{\circ} \mathrm{C}$ warmer than the inlet air. The constant heat flux light fixture boundary condition without radiation results in a uniformly heated beam tube.

Figure 3 presents results from the light fixture boundary condition corresponding to a constant surface heat flux with radiation heat transfer. In this model, the dissipation of the $105.6 \mathrm{~W}$ of energy from the light fixture is partitioned between convection and radiation heat transfer. This partition, as summarized in Table 1 , is $24.6 \mathrm{~W}$ by convection and $81.0 \mathrm{~W}$ by radiation. This partition, which is consistent with previous experiments [10], was created by adjusting the light fixture surface emissivity to a value of 0.6 . The light fixture surface temperature predicted with this model is $322.4 \mathrm{~K}$, which is a much 

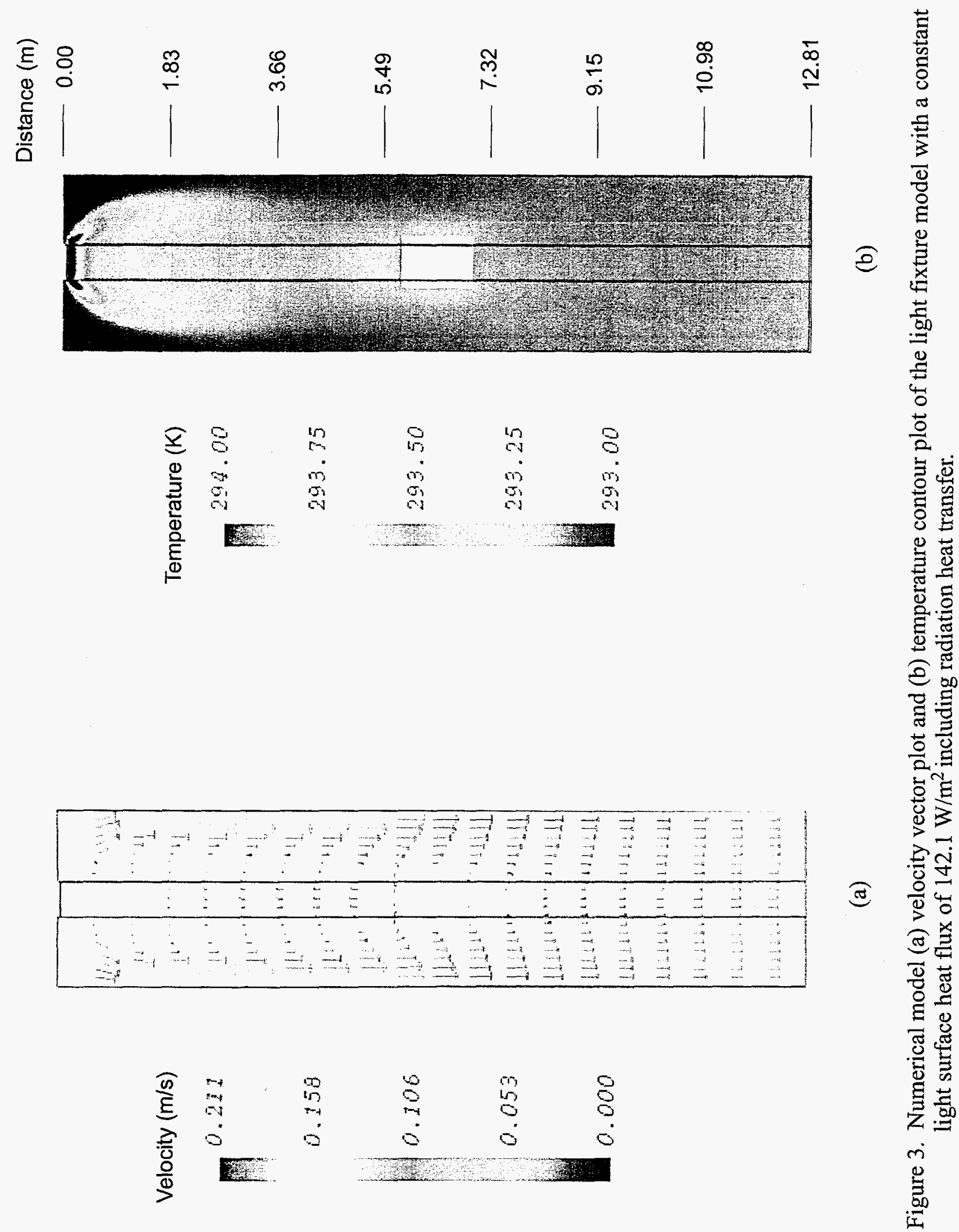

范

을

ล

党

욤

孚 

more reasonable surface temperature for a fluorescent light fixture [10] than the temperature predicted in the previous model that neglected radiation heat transfer.

Noticeable differences are observed when comparing the velocity vector plot of Figure 3(a), predicted with the inclusion of radiation heat transfer, with that of Figure 2(a), predicted without radiation exchange. In the velocity vector plot of Figure 3(a), while similar to Figure 2(a), the outward push of the fluid near the light fixture is noticeably less. This is a result of reduced buoyancy forces created by only $24.6 \mathrm{~W}$ entering the gas by convection in the plot of Figure 3(a), compared with the $105.6 \mathrm{~W}$ convected in Figure 2(a). Comparing Figure 3(b) with Figure 2(b), the hot thermal zone near the light fixture is smaller in extent and in intensity, as expected. In addition, Figure 3(b) reveals that a small thermal plume exists on the top surface of the beam tube. Radiation heating of the upper beam tube surface by the light fixture creates a hot surface that dissipates heat by convection to the cooler air in the form of a vertical convective plume. Since the bottom side of the beam tube is not exposed directly to the radiation heat exchange from the light fixture, a temperature differential is created between the upper and lower beam tube surfaces. This temperature difference could lead to appreciable beam pointing errors $[10,13]$.

In choosing a constant surface temperature rather than a constant surface heat flux boundary condition to represent a heat-generating surface, extreme care must be taken to ensure that the correct amount of heat is being dissipated by the representative surface. For example, if a $100 \mathrm{~W}$ air heater is being modeled as a constant temperature surface, the temperature value must be chosen correctly so that $100 \mathrm{~W}$ of power passes through the heater surface. The temperature value that satisfies the energy balance will depend on 
such things as the surrounding gas physical properties, gas velocity, and whether or not radiation heat transfer is being accounted for. Thus, unlike the constant surface heat flux boundary condition in which the surface temperature is calculated to satisfy the energy balance, the constant surface temperature boundary condition must be manipulated to converge on a correct energy balance. As will be shown with the following two CFX models, the constant surface temperature boundary condition can lead to significant energy balance discrepancies, especially if radiation heat transfer is neglected.

Figure 4 presents results from the light fixture boundary condition corresponding to a constant surface temperature with radiation heat transfer. The light fixture surface temperature selected in the model corresponding to Figure 4 was $322.4 \mathrm{~K}$, which corresponds to the most realistic value determined with the constant heat flux/radiation model (Figure 3). Since the physical properties and inlet velocity of the gas are the same for the constant heat flux and surface temperature boundary conditions for the models depicted in Figure 3 and Figure 4, respectively, and since radiation heat transfer is included in both models, the temperature fields for both models are identical (see Table 1). This is expected since the constant surface temperature model has the same light fixture boundary temperature and heat transfer processes as the constant surface heat flux model. 


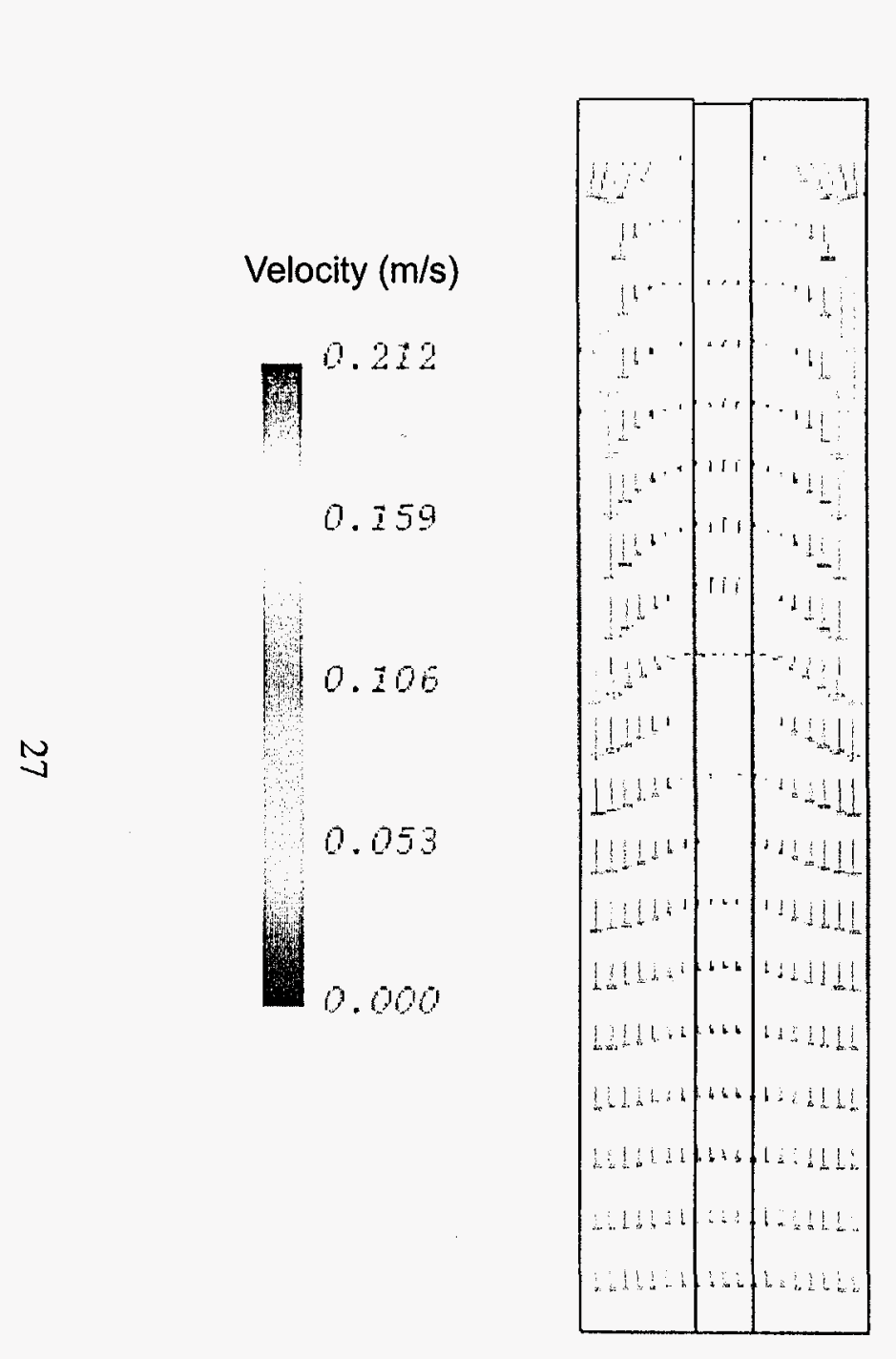

(a)

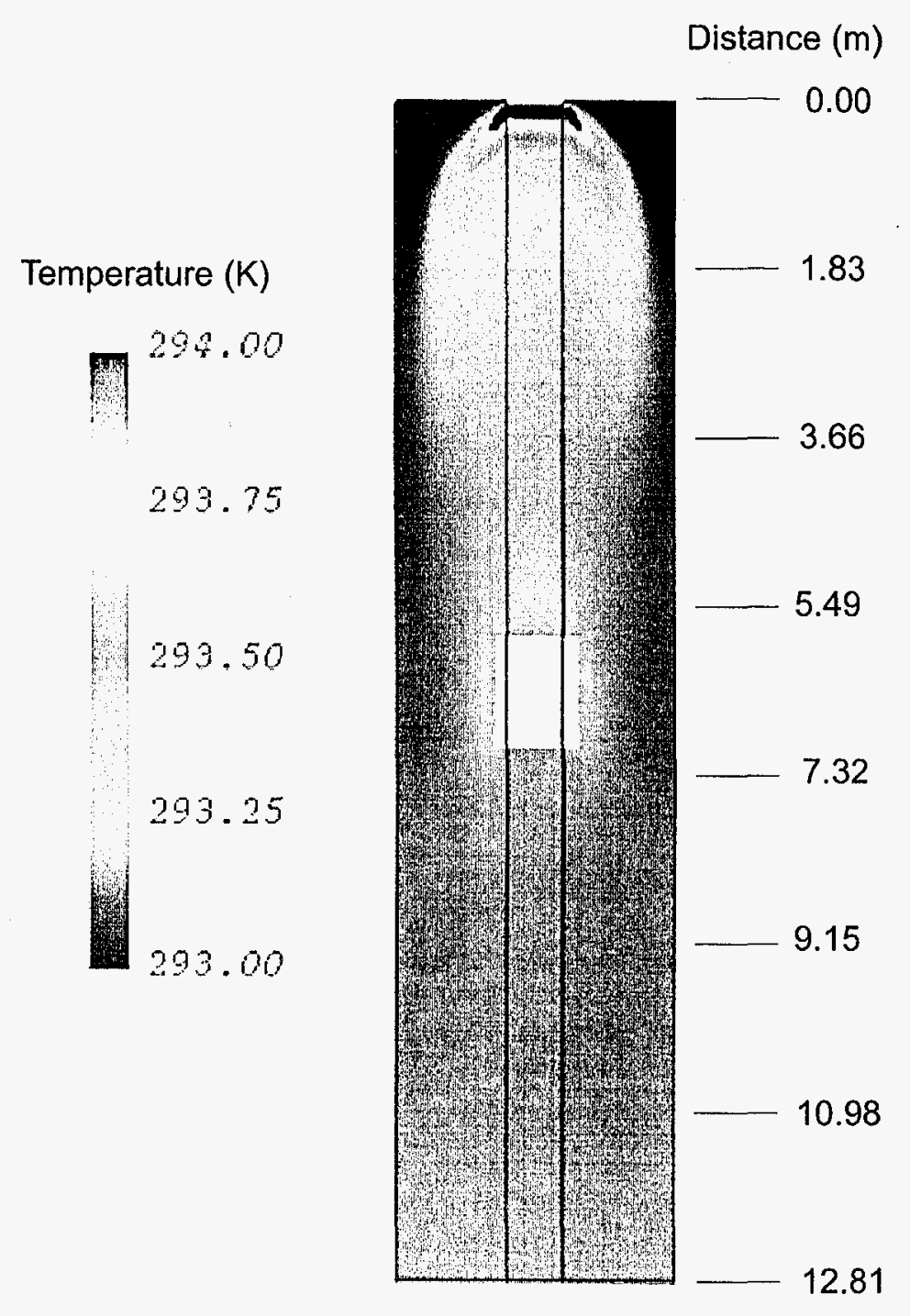

(b)

Figure 4. Numerical model (a) velocity vector plot and (b) temperature contour plot of the light fixture model with a constant light surface temperature of $322.4 \mathrm{~K}$ including radiation heat transfer. 

If radiation heat transfer is removed from the constant surface temperature model, convection heat transfer will be the sole means for removing heat from the light fixture. If in addition, the surface temperature boundary condition value is unaltered, the amount of heat dissipated by the light fixture will be significantly less than that predicted with the presence of radiation heat transfer.

Figure 5 presents results from the light fixture boundary condition corresponding to a constant surface temperature of $322.4 \mathrm{~K}$ and no radiation heat transfer. As mentioned previously, this surface temperature is realistic for a fluorescent light fixture and $322.4 \mathrm{~K}$ was calculated as the light fixture temperature when the constant heat flux boundary condition was employed (see Figure 3). As the data of Table 1 indicates, this current model predicts that only $24.7 \mathrm{~W}$ is dissipated by convection from the $105.6 \mathrm{~W}$ light fixture. The remaining $80.9 \mathrm{~W}$ that should be dissipated by radiation (as predicted by the model corresponding to Figure 4) is neglected with the absence of the radiation heat exchange model. Comparison of the velocity vector and temperature contour plots of Figure 4 and Figure 5 indicates that while the presence of radiation heat transfer does not influence the flow field near the light fixture, it does significantly affect the surface temperature and flow pattern near the top of the beam tube. Consequently, neglecting radiation heat transfer not only presents an unsatisfied energy balance on the light fixture, it also leads to unrealistic temperature and flow fields near radiatively participating surfaces.

In summary, if a realistic surface temperature is used as a boundary condition on a heat generating object, but radiation heat transfer is neglected in the modeling, the 


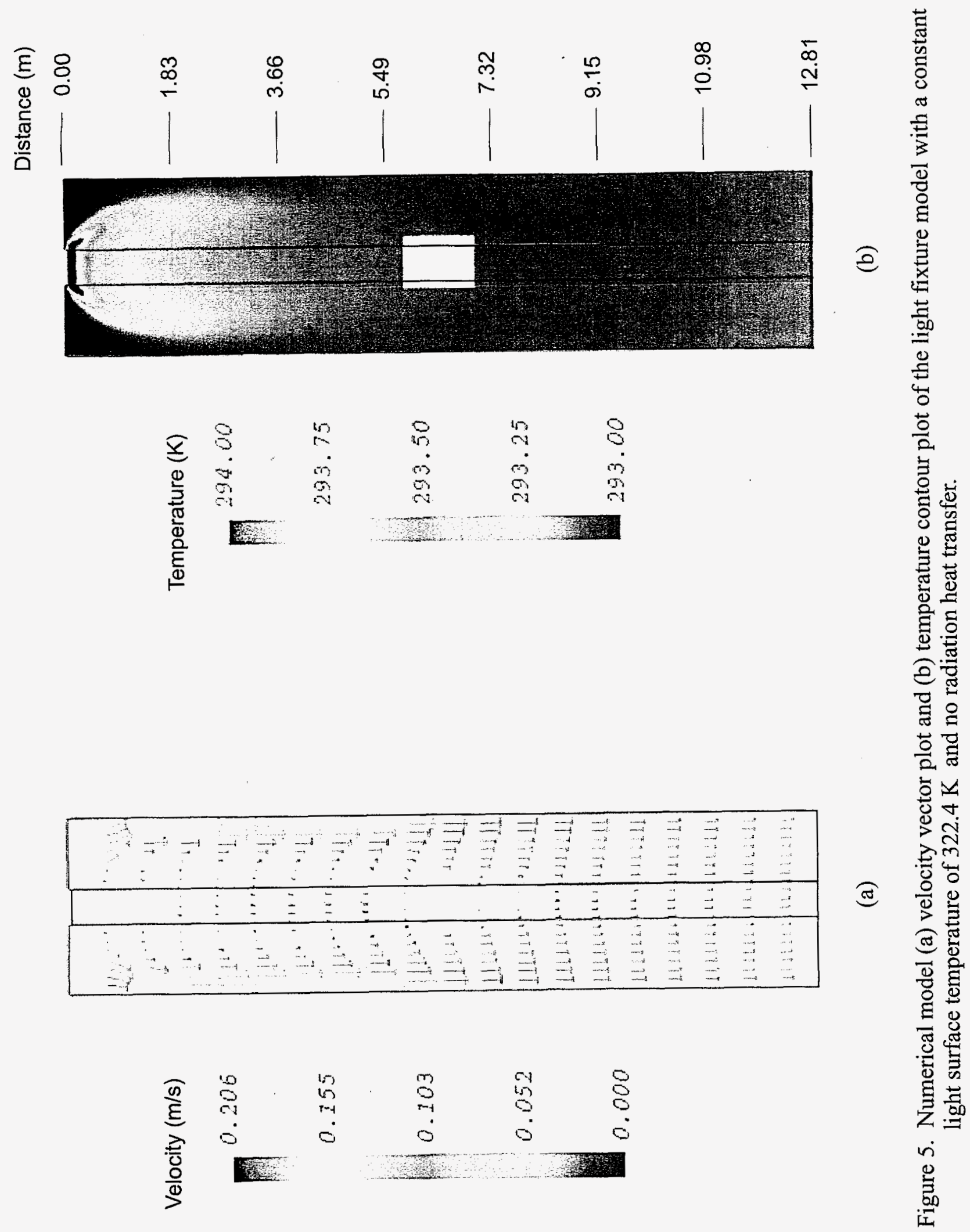



amount of heat dissipated from that surface could be significantly less than the actual power dissipation of the object. In addition, the absence of radiation heat transfer could lead to unrealistic temperature and flow fields near radiatively participating surfaces. As mentioned earlier, this is consistent with the findings of several previous studies $[4,5,6$, 7].

\section{Summary Remarks and Conclusions}

The objectives of this report were to provide general guidelines on the technical approach to performing and interpreting any and all CFD calculations, and to document results from NIF-related, two-dimensional CFD light fixture case studies illustrating these guidelines. In particular, a CFD study was conducted to investigate the strengths and deficiencies in modeling a fluorescent light fixture as either a constant surface heat flux or constant surface temperature boundary condition, both with and without radiation heat transfer. The results of this study support a number of general conclusions.

(1) Several means exist for determining the convergence and accuracy of a CFD model solution. These include checks for grid independence, convergence of the dependent variable residuals, mass and energy balances, and comparison with experimental data.

(2) While the energy dissipation characteristics of a light fixture are extremely complex, a reasonable and conservative approximation can be made as to the thermal effect of a light fixture on a ventilated space. 
(3) Either constant heat flux or constant temperature boundary conditions can be used to inject the rated power of a light fixture. However, the constant heat flux boundary condition with radiation heat transfer is most appropriate because it captures the true heat transfer mechanisms and ensures an accurate energy balance on the light fixture. The light fixture emissivity can be adjusted to set the partition between convection and radiation heat transfer in both cases. For the constant temperature case, the light fixture temperature must be adjusted or corrected until the model provides an accurate energy balance with realistic surface temperature values.

(4) Radiation effects are non-negligible when modeling light fixture heat input to ventilated spaces and are the dominant heat transfer effect.

(5) If for practical reasons or code limitations radiation is neglected in such calculations, we are well advised to at least check the heat injection against the light fixture rated power.

\section{REFERENCES}

[1] Anderson, D. A. et al., 1984, Computational Fluid Mechanics and Heat Transfer, Hemisphere Publishing Corp., Washington.

[2] Incropera, F. P. and DeWitt, D. P., 1996, Fundamentals of Heat and Mass Transfer, 4th Ed., John Wiley and Sons, New York.

[3] Akiyama M. and Chong, Q. P., 1997, "Numerical Analysis of Natural Convection with Surface Radiation in a Square Enclosure," Numerical Heat Transfer, Part A, Vol. 31, pp. 419-433. 
[4] Dehghan, A. A. and Behnia, M., 1996, "Combined Natural Convection-Conduction and Radiation Heat Transfer in a Discretely Heated Open Cavity," ASME J. Heat Trans., Vol. 118, pp. 56-64.

[5] Carpenter, J. R., Briggs, D. G., and Sernas, V., 1976, "Combined Radiation and Developing Laminar Free Convection Between Vertical Flat Plates with Asymmetric Heating, " ASME J. Heat Trans., Vol. 98, pp. 95-100.

[6] Larson, D. W. and Viskanta, R., 1976, "Transient Combined Laminar Free Convection and Radiation in a Rectangular Enclosure," J. Fluid Mech., Vol. 78, pp. 65-85.

[7] White, F. M., 1974 Viscous Fluid Flow, McGraw-Hill, Inc.

[8] American Society of Heating, Refrigerating, and Air Conditioning Engineers, Inc., ASHRAE Fundamentals Handbook, I-P Edition, ASHRAE, Atlanta GA, 1993, pp. $26.7 \mathrm{ff}$.

[9] Marks' Standard Handbook for Mechanical Engineers, 10th ed., edited by E. A. Avallone and T. Baumeister III, McGraw-Hill Co., Inc., New York, NY, 1996, pp. 12-116.

[10] Bernardin, J. D., Parietti, L., and Martin, R. A., 1997, "Thermal Issues Associated with the HVAC and Lighting Systems Influences on the Performance of the National Ignition Facility Beam Transport Tubes," Los Alamos National Laboratory Report LA-13410-MS.

[11] S. V. Patankar and D. B. Spalding, 1972, "A Calculation Procedure for Heat, Mass and Momentum Transfer in Three-Dimensional Parabolic Flows," Int. J. Heat Mass Trans., Vol. 15, pp. 1787-1806.

[12] Van Doormaal, J. P. and Raithby, G. D., 1984, "Enhancements of the SIMPLE Method for Predicting Incompressible Fluid Flows," Numerical Heat Transfer, Vol. 7 , pp. 147-163.

[13] Murray, J., 1997, "Back-of-the-Envelope Analysis of Gas in Beam Tubes," Internal Memo for National Ignition Facility Project, NIF-0001838, WBS 1.4.1.2, March 27, Livermore, CA. 